\title{
Ciliary dyskinesia is an early feature of respiratory syncytial virus infection
}

\author{
Claire M. Smith ${ }^{1,2,3}$, Hemant Kulkarni ${ }^{3}$, Priya Radhakrishnan ${ }^{3}$, Andrew Rutman $^{3}$, \\ Michael J. Bankart ${ }^{4}$, Gwyneth Williams ${ }^{3}$, Robert A. Hirst ${ }^{3}$, Andrew J. Easton ${ }^{5}$, \\ Peter W. Andrew ${ }^{3}$ and Chris $0^{\prime}$ Callaghan ${ }^{1,2,3}$
}

\author{
Affiliations: \\ 'Dept of Respiratory Medicine, Portex Unit, University College London, Institute of Child Health, London, \\ ${ }^{2}$ Great Ormond Street Hospital, London, \\ ${ }^{3}$ Dept of Infection, Immunity and Inflammation, University of Leicester, Leicester, \\ ${ }^{4}$ Health Services Research Unit, Keele University, Keele, and \\ ${ }^{5}$ School of Life Science, University of Warwick, Coventry, UK.

\section{Correspondence:} \\ C. O'Callaghan, Dept of Respiratory Medicine, Portex Unit, Institute of Child Health, University College London \\ (UCL), 30 Guilford Street, London, WC1N 1EH, UK. \\ E-mail: c.ocallaghanducl.ac.uk
}

ABSTRACT Respiratory syncytial virus is a major cause of respiratory disease. There are conflicting accounts of the response of human epithelial cells to respiratory syncytial virus and a lack of data on its effect on ciliary function. Our aim was to study the early stages of respiratory syncytial virus infection of primary human basal and ciliated cultures.

Using high speed videomicroscopy, we found that ciliary beat frequency was unaffected by respiratory syncytial virus infection over $72 \mathrm{~h}$; however, ciliary dyskinesia significantly increased within $24 \mathrm{~h}$ of infection $(\mathrm{p}<0.05)$. Transmission electron microscopy revealed that ultrastructural abnormalities were confined to ciliated cells, including increased cilia loss and mitochondrial damage. Confocal immunofluorescence microscopy showed that respiratory syncytial virus antigen gradually spread from the cell surface to the ciliary tip of infected cells over 3 days. Interestingly, ciliated cultures secreted fewer viruses than basal (progenitor) cell cultures and produced a chemokine response focused on recruitment of neutrophils.

This study highlights differences in infection models and underscores the need to explore further the role of ciliated cells in the establishment of respiratory syncytial virus infection.

Increased ciliary dyskinesia combined with ciliary loss and epithelial damage is likely to result in reduced mucociliary clearance early in the infective process.

@ERSpublications

Increased ciliary dyskinesia with ciliary loss and epithelial damage can result in reduced mucociliary clearance http://ow.ly/qALuA 


\section{Introduction}

Respiratory syncytial virus (RSV) is the major cause of hospitalisation of children with respiratory disease aged $<1$ year worldwide and it infects almost every child by age 2 years [1]. Recent evidence suggests that the virus initiates infection by targeting human ciliated epithelium lining the nasopharynx [2-4]. We have previously shown that nasal brush biopsies from hospitalised infants with bronchiolitis exhibited significant disruption of the ciliated epithelium during RSV infection, with recovery taking many weeks [5]. More recently ciliated human respiratory epithelium in culture has been used to explore the early effects of RSV infection. These studies have produced conflicting results. While one study reported marked cellular disruption and very rapid ciliostasis after the addition of RSV [6], others report no cytopathic effects $[2,7,8]$ and no effect on ciliary beat frequency (CBF) [2] over many days, suggesting little effect on the ciliary component of mucociliary clearance. However these studies have lacked evaluation of a crucial aspect of ciliary function, ciliary beat pattern. We have previously shown that in certain phenotypes of primary ciliary dyskinesia, where mucociliary clearance is grossly reduced, all the cilia beat in a dyskinetic fashion, despite CBF being maintained at a normal level $[9,10]$. In addition, we have shown that the infection of healthy volunteers with coronavirus caused epithelial damage and gross ciliary dyskinesia, but did not affect CBF [11].

The primary aim of this study was to evaluate the early effect of RSV infection on the beat pattern and frequency of human ciliated epithelial cells in culture, to test the hypothesis that RSV infection would significantly increase ciliary dyskinesia. The second aspect of our study was to investigate the preference of RSV to infect ciliated cells and to compare the effect of RSV in two infection models: human basal cell and ciliated cell cultures. To do this we evaluated the pattern of viral antigen spread in basal and ciliated cell cultures using immunofluorescence microscopy. We also studied the pattern of cytokine and chemokine secretion from the apical surfaces of the basal and ciliated cell cultures.

\section{Materials and methods}

Subjects

Human nasal epithelial cells were obtained from healthy control subjects $(n=9)$ aged median (range) 21 (19-49) years who had no history of nasal or respiratory disease. None of the subjects was taking medications and none had reported a symptomatic upper respiratory tract infection in the preceding 6 weeks. All individuals gave their consent to be included in the study and all samples were obtained with the individual's permission and with ethical approval by the University of Leicester Committee for Research Ethics (Leicester, UK).

\section{Respiratory epithelial cell culture}

Human ciliated epithelium was obtained by brushing the inferior nasal turbinate with a 2-mm cytology brush (Keymed, Southend-on-Sea, UK) as previously described [9]. The ciliated epithelial sample was vigorously pipetted into $2 \mathrm{~mL} 20 \mathrm{mM}$ HEPES-buffered medium 199 ( $\mathrm{pH}$ 7.4) (Gibco Life Technologies, Paisley, UK), containing penicillin $\left(100 \mathrm{IU} \cdot \mathrm{mL}^{-1}\right)$, streptomycin $\left(100 \mu \mathrm{g} \cdot \mathrm{mL}^{-1}\right)$ and fungizone $\left(2.5 \mu \mathrm{g} \cdot \mathrm{mL}^{-1}\right)$ to break-up large cell clumps and kept at $4^{\circ} \mathrm{C}$ overnight. $1 \mathrm{~mL}$ was then placed in a collagen coated well of a 12-well plate (Sigma-Aldrich, Poole, UK) together with $1 \mathrm{~mL}$ basal epithelial growth medium (BEGM), containing penicillin $\left(100 \mathrm{IU} \cdot \mathrm{mL}^{-1}\right)$, streptomycin $\left(100 \mu \mathrm{g} \cdot \mathrm{mL}^{-1}\right)$ and fungizone $\left(2.5 \mu \mathrm{g} \cdot \mathrm{mL}^{-1}\right)$, at $37^{\circ} \mathrm{C}$. The medium bathing the basal cells was replaced every 2-3 days. When the cells were $>90 \%$ confluent the cells were detached using trypsin/EDTA (Sigma-Aldrich) for $5 \mathrm{~min}$. The cells were then centrifuged $(4000 \times g$ for $10 \mathrm{~min}$ ) and the supernatant removed. The pellet was resuspended in BEGM to a concentration of $1 \times 10^{6}$ cells $\cdot \mathrm{mL}^{-1} .400 \mu \mathrm{L}$ cell suspension was added to each well of a 24 -well plate (Sigma-Aldrich) or LabTekII Chambered Coverglass slide (for acquiring high-resolution images) and grown until $\geqslant 80 \%$ confluent.

The remaining basal cells were seeded on collagen-coated, semipermeable membrane supports (TranswellCol; $12 \mathrm{~mm}$ in diameter; $0.4-\mu \mathrm{m}$ pore size; Corning-Costar, Corning) as previously described [12]. At $80 \%$ confluence, the apical medium was removed and the cells were maintained at an air-liquid interface (ALI) to allow differentiation of the epithelial subtypes. Well-differentiated cultures were studied $\sim 4-6$ weeks after initiation of an ALI culture, unless otherwise stated. Cells obtained from two individuals produced basal cell and ALI cultures that were used for experimentation.

\section{Virus strains and growth conditions}

Wild-type RSV strain A2 stocks were prepared in monolayers of BSC-1 monkey kidney cells in antibioticfree Glasgow's minimum essential medium supplemented with nonessential amino acids and 2\% (v/v) fetal calf serum at $5 \% \mathrm{CO}_{2}$ and $37^{\circ} \mathrm{C}$. Stocks were harvested by disruption with glass beads for $1 \mathrm{~min}$ and the supernatant was centrifuged at $1000 \times g$ for $5 \mathrm{~min}$ to remove cell debris. The filtrate was then purified by centrifugation through a polyethersulfone membrane with a pore size of $1000 \mathrm{kDa}$ molecular weight cut-off (Vivaspin-20; Vivascience, Gloucester, UK), as previously described [13]. The virus fractions were collected 
and pooled in bronchial epithelial cell basal medium (BEBM; Lonza, Slough, UK), and aliquots containing about $0.5-1 \times 10^{6}$ plaque-forming units $(\mathrm{PFU}) \cdot \mathrm{mL}^{-1}$ were stored at $-80^{\circ} \mathrm{C}$.

\section{Viral infection of primary epithelial cell cultures}

Frozen aliquots of RSV were thawed immediately prior to use. For basal cell infections, $400 \mu \mathrm{L}$ viral suspension (multiplicity of infection (MOI) of $\sim 0.1 \mathrm{PFU}$ per cell) diluted in BEBM was applied for $1 \mathrm{~h}$ at $37^{\circ} \mathrm{C}$. Control wells received BEBM alone. After this time, the virus inoculum was removed and the cells were incubated in BEGM. The infection was allowed to continue for a further $72 \mathrm{~h}$. At this time, the supernatants were harvested and stored at $-70^{\circ} \mathrm{C}$ for cytokine analyses.

For ALI culture infection, the apical surface of the ALI cultures was rinsed with medium (BEBM) and $200 \mu \mathrm{L}$ viral inoculum (MOI of $\sim 0.1$ PFU per cell) in BEBM was applied to the apical surface for $1 \mathrm{~h}$ at $37^{\circ} \mathrm{C}$ and then removed. Control wells received BEBM alone. All cells were fed basolaterally with fresh ALI medium prior to infection. The infection was allowed to continue for 20-72 h. After this time the apical surface was again rinsed with medium, which was collected and stored at $-70^{\circ} \mathrm{C}$ for cytokine analyses. Cells were fixed overnight with $4 \%(\mathrm{v} / \mathrm{v})$ paraformaldehyde in PBS for immunostaining.

\section{CBF and beat pattern}

To determine changes in ciliary activity, respiratory cells in culture were placed in an incubation chamber at $37^{\circ} \mathrm{C}$ and were observed via an inverted microscope system (Nikon TU1000; Nikon, Kingston-uponThames, UK) equipped with a motorised stage. Cultures were allowed to equilibrate for 30 min before readings. Prior to infection, the location coordinates of five different ciliated areas from each Transwell insert were saved using NIS Elements AR software (Nikon) to allow repeated observation of the same areas. Beating cilia were recorded using a trouble-shooter digital high-speed video camera (Lake Image Systems, Henrietta, NY, USA) at a rate of 250 frames per second using a $40 \times$ objective as previously described [9]. The number of motile ciliated cells in each sample area was counted (motility index) and half were used to determine the average CBF. The CBF of individual ciliated cells was determined by counting the number of frames required for five full sweeps of a clearly observed ciliary tip. This was converted to CBF by a simple calculation $(\mathrm{CBF}=250 /$ (number frames for five beats $) \times 5)$ [9]. Ciliary dyskinesia was defined as ciliated cells that displayed uncoordinated motile cilia or those that beat with a stiff, flickering or twitching motion. The dyskinesia index was calculated as the percentage of dyskinetic ciliated cells relative to the total number of motile ciliated cells. The video sequences were analysed by two observers (C. Smith and P. Radhakrishnan); the second observer (P. Radhakrishnan) was blinded to the treatment and timepoint recorded.

\section{Chemokine and cytokine analysis}

Chemokines and cytokines were measured using a 96-well multispot assay (Meso Scale Discovery (MSD), Rockville, MD, USA) according to the manufacturer's instructions. Cytokines were measured using a human T-helper cell (Th1/Th2) type standard 10 spot plate and human chemokines were measured using a high band MS6000 10-spot plate, using SECTOR Imager 6000 (MSD). The lower limit of detection was $1 \mathrm{pg} \cdot \mathrm{mL}^{-1}$.

\section{Immunofluorescence microscopy}

Cells were flxed with $4 \%(\mathrm{v} / \mathrm{v})$ paraformaldehyde in PBS overnight at $4{ }^{\circ} \mathrm{C}$. Following flxation, cells were washed three times with PBS, treated with $3 \%(\mathrm{w} / \mathrm{v})$ bovine serum albumin (BSA) in PBS for $10 \mathrm{~min}$ to block nonspecific interactions, and washed again three times with PBS. All subsequent antibody incubations were carried out in PBS containing 1\% (weight/volume) BSA. Reagents used for immunofluorescence in this study were goat anti-RSV polyclonal antibody (ab20745; $40 \mu \mathrm{g} \cdot \mathrm{mL}^{-1}$; Abcam, Cambridge, UK) and mouse anti-acetylated $\alpha$-tubulin monoclonal antibody (clone $6-11 \mathrm{~B}-1 ; 1 \mu \mathrm{g} \cdot \mathrm{mL}^{-1}$; Sigma). Primary antibody incubations were carried out for $2 \mathrm{~h}$, followed by three washes with PBS. Detection of primary antibodies was carried out for $2 \mathrm{~h}$ using the following secondary reagents: fluorescein isothiocyanateconjugated rabbit anti-goat (1:200; Sigma) or AlexaFluor 594-conjugated rabbit anti-mouse antibody (1:250; Invitrogen, Paisley, UK). All secondary antibodies had been tested and found to be negative for cross-reactivity against human epithelial cells. DNA was stained with Hoechst $33258\left(0.2 \mu \mathrm{g} \cdot \mathrm{mL}^{-1}\right)$. Following three final washes in PBS, the insert was cut from the support and mounted under coverslips in $80 \%(\mathrm{v} / \mathrm{v})$ glycerol, $3 \%(\mathrm{w} / \mathrm{v}) n$-propylgallate (in PBS) mounting medium. Low magnification images were acquired using a Nikon TU1000 inverted microscope equipped with NIS Elements software that enabled the acquisition of images of entire wells. High resolution optical sections were obtained using a Leica TCS SP5 confocal microscope equipped with a Leica DMI 6000B inverted microscope (Leica, Milton Keynes, UK) using a $63 \times$ oil objective (numerical aperture, 1.4). Images acquired by confocal microscopy were rendered by Imaris Software (Bitplane AG, Zurich, Switzerland) using the blend or maximum intensity projection filters. 


\section{Transmission electron microscopy}

In a recent study we used transmission electron microscopy (TEM) to show cilia loss is a feature of patients with severe asthma [14]. To determine whether RSV infection also led to cilia loss, we obtained three additional samples from healthy control subjects (median (range) age 29 (24-58) years) by brushing the bronchus intermedius (by flexible bronchoscopy), and cultured and infected the ciliated cells as before. Following infection, cells were fixed in $4 \%(\mathrm{v} / \mathrm{v})$ glutaraldehyde and processed as described previously [14].

\section{Statistical analysis}

Statistical analysis was performed using GraphPad Prism 5 (GraphPad, San Diego, CA, USA). CBF (expressed in hertz) was determined following random selection of cilia. Any difference in the ciliary activity observed for control and RSV was determined using paired t-tests. Nonparametric data were described as median (interquartile range). Within-group comparisons of the magnitude of chemokine/cytokine release were performed using a Wilcoxon signed ranks test. Between groups comparisons were performed using the Mann-Whitney U-test.

\section{Results}

The effect of RSV infection on ciliary function

Ciliated nasal epithelial cells showed a higher proportion of dyskinetic cilia following RSV infection (table 1). The median (interquartile range) dyskinesia index was significantly increased $(\mathrm{p}<0.05)$ as early as $24 \mathrm{~h}$ post-RSV infection $(21(17-25) \%)$ compared with controls $(10(2-13) \%)$. This increased $(\mathrm{p}<0.05)$ further to 33 (25-42)\% after $72 \mathrm{~h}$ of RSV infection compared with controls 13 (11-14)\%. Despite changes in ciliary beat pattern, the CBF of ciliated nasal epithelial cells in culture was unaffected by RSV infection over the 72-h study period. The median (interquartile range) CBF of RSV-infected nasal ciliated cells was the same after $72 \mathrm{~h}(10.8(10.5-11.7) \mathrm{Hz})$ as the uninfected controls $(10.3(10.1-12.7) \mathrm{Hz})(\mathrm{p}=0.87)$. The number of ciliated cells with motile cilia, observed by light microscopy, was also unaffected by RSV infection. The median (interquartile range) motility index for ciliated nasal epithelial cells was similar $72 \mathrm{~h}$ post-RSV infection $(22(18-29) \%)$ compared with the uninfected controls $(20(18-28) \%)(\mathrm{p}=0.88)$.

\section{RSV antigen is absent from the ciliary axoneme during early infection of human ciliated} epithelial cells

To investigate the spread of viral antigen in ciliated epithelial cells the cells were fixed $20-72 \mathrm{~h}$ postinfection and stained with antibodies specific for cilia (acetylated tubulin) and RSV proteins ( $G$ and $F$ ), which are present on the surface of infected cells. Nonciliated cells, including club cells (Clara cells) and goblet cells, remained unstained. It was found that the majority of cells that displayed positive staining for RSV antigen were also positively stained for cilia, indicating preferential infection of ciliated cells (observation, not quantified). Reconstruction of confocal z-sections of RSV-infected cells showed that as infection progressed, the pattern of localisation of RSV antigens on the cell surface of the ciliated cell altered. No viral antigens were observed in the control wells (figs $1 \mathrm{a}-\mathrm{d}$ and $\mathrm{m}-\mathrm{o}$ ). At $20 \mathrm{~h}$ post-infection, RSV antigens ( $G$ and $F$ ) were observed on the apical surface of ciliated cells, but no antigen was seen on the ciliary axoneme (fig. 1e-h). Between 24 and $72 \mathrm{~h}$ post-infection, an increasing amount of RSV antigen was observed on the apical surface of the cell and on the ciliary axoneme, which was confirmed by the co-localisation of RSV antigen and acetylated tubulin antigen (fig. 1i-1). Optical sections of these images confirmed these findings. At $20 \mathrm{~h}$ post-infection (fig. $1 \mathrm{p}-\mathrm{r}$ ) no antigen was seen on the ciliary axoneme

TABLE 1 The ciliary beat frequency, motility index and dyskinesia index of healthy nasal respiratory epithelial cells in pseudostratifled air-liquid interface cultures infected with respiratory syncytial virus (RSV) A2

\begin{tabular}{|c|c|c|c|c|c|c|}
\hline \multirow[t]{2}{*}{ Time $\mathbf{h}$} & \multicolumn{2}{|c|}{ Ciliary beat frequency $\mathrm{Hz}$} & \multicolumn{2}{|c|}{ Motility index ${ }^{\#}$} & \multicolumn{2}{|c|}{ Dyskinesia index \% } \\
\hline & Control & RSV-infected & Control & RSV-infected & Control & RSV-infected \\
\hline 24 & $12.5(12.2-13.2)$ & $12.4(10.9-13.7)$ & $12.0(11.0-15.0)$ & $13.5(12.0-15.0)$ & $10.0(2.0-12.5)$ & $20.8(16.7-25.0)^{*}$ \\
\hline 48 & $13.1(11.9-14.5)$ & $12.0(11.9-12.9)$ & $9.0(8.0-12.0)$ & $9.0(8.0-12.0)$ & $11.1(8.3-12.5)$ & $35.0(23.1-36.4)^{*}$ \\
\hline 72 & $10.3(10.1-12.7)$ & $10.8(10.5-11.7)$ & $9.0(8.0-13.0)$ & $10.0(8.0-13.0)$ & $12.5(11.1-14.3)$ & $33.3(25.0-41.7)^{*}$ \\
\hline
\end{tabular}

Data are presented as median (interquartile range). ${ }^{*}$ : number of motile ciliated cells per sample area of $\sim 4.2 \mathrm{~mm}^{2}$; ${ }^{\circ}$ : percentage of dyskinetically beating cilia amongst all cilia examined. *: $p<0.05$. 

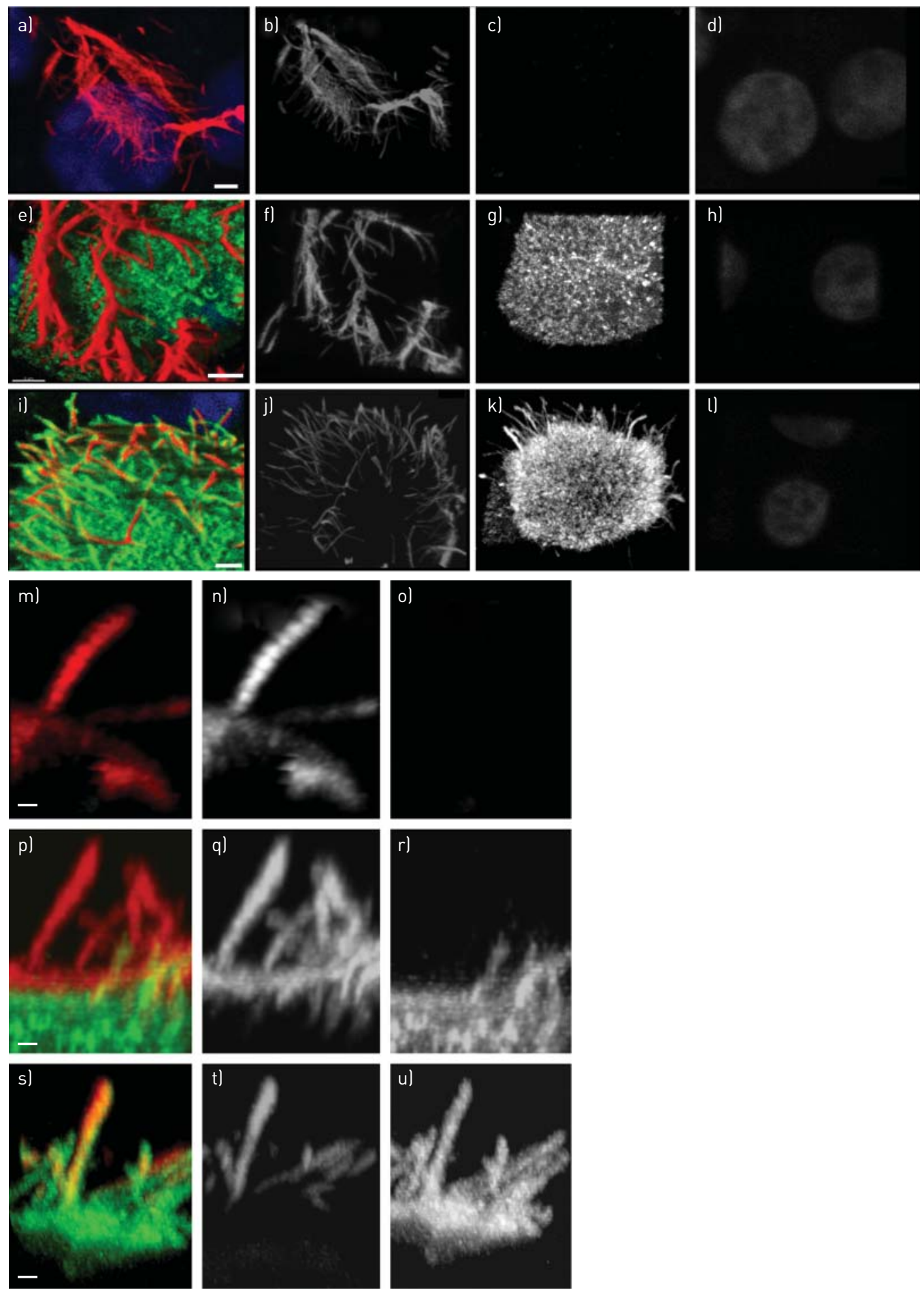

FIGURE 1 Confocal images of respiratory syncytial virus (RSV)-infected human nasal ciliated epithelial cells grown at an air-liquid interface. Cells were co-stained with antibodies against acetylated tubulin to detect the axonemal microtubules (AlexaFluor 594; red in merge) and a polyclonal antibody for RSV antigens (fluorescein isothiocyanate; green in merge). Nuclei were stained using Hoescht (blue in merge). Merged images are shown in panels a), e) and i), where yellow indicates areas of RSV-tubulin antigen colocalisation. a-d) Noninfected control cells showing cilia staining only; no viral antigens were observed. e-h) RSV-infected ciliated epithelial cells 20-24 h post-infection showing viral antigen displayed on the surface of the cell but not the cilial shaft. i-1) RSV-infected ciliated epithelial cells $72 \mathrm{~h}$ post-infection showing viral antigens on the surface of the cell and the full length of the cilial shaft. $\mathrm{m}-\mathrm{u}$ ) optical sections of a-l), respectively. Threedimensional reconstruction of all channels was performed with Imaris (Bitplane AG, Zurich, Switzerland) blend filter. Scale bars $=2 \mu \mathrm{m}$. 
whereas at $72 \mathrm{~h}, \mathrm{RSV}$ and tubulin antigen co-localisation extended over the full length of the ciliary axoneme (fig. 1s-u).

\section{Ultrastructural damage following RSV infection was confined to ciliated cells}

In a recent study, TEM was used to show cilia loss is a feature of patients with severe asthma [14]. To determine whether RSV infection also led to cilia loss, three additional samples were obtained and TEM was performed on cultured ciliated epithelium that had been infected with RSV (or mock infected) for $72 \mathrm{~h}$. The median (interquartile range) number of epithelial cells per sample studied was 339 (303-360). Results are summarised in table 2 and example electron micrographs are shown in figure 2. The ultrastructure of the ciliated epithelium was abnormal following RSV infection with more ciliated cells (60 (48-70)\%) exhibiting loss of cilia compared to the control $(40(36-44) \%)(\mathrm{p}<0.001)$. There was also a significant increase $(\mathrm{p}<0.01)$ in the percentage of ciliated cells with mitochondrial damage. This increased from $24(18-25) \%$ in the control wells to $40(28-45) \%$ in the RSV-infected wells. No significant increase $(p=0.36)$ in the percentage of nonciliated cells with mitochondrial damage was observed following RSV infection. The proportion of ciliated cells in the epithelium remained unchanged following RSV infection.

\section{Human basal cell cultures display a higher proportion of RSV-infected cells than ciliated cultures} after $72 \mathrm{~h}$

Primary basal epithelial cells have been shown to resist infection following basolateral inoculation or trauma to pseudo-stratified ciliated cell cultures [2, 4]. However, WRiGHT et al. [8] showed that RSV grew to a significantly lower titre in ciliated adenoid cultures than in the HEp-2 cell line. However, their study compared primary cells to an immortalised cell line, and their two growth states could have confounded interpretation of the data. To investigate this further, primary human basal cell cultures were infected with the same infective dose of RSV as was used for the primary ciliated cultures. After $72 \mathrm{~h}$ infection, the number of RSV-infected cells and the level of inflammatory mediator production was assessed. Lowmagnification scans of cells infected for $72 \mathrm{~h}$ indicated that there were considerably more RSV-positive cells in basal cell cultures compared witho ciliated cell cultures after $72 \mathrm{~h}$ (figs $3 \mathrm{a}$ and b). Viral titration of the cell culture supernatants confirmed these findings (fig. $3 c$ ), with significantly $(p=0.02)$ higher titres of infective RSV detected in the cell culture supernatant recovered from basal cell cultures (mean $\left.1.5 \times 10^{4} \mathrm{PFU} \cdot \mathrm{mL}^{-1}\right)$ than from ciliated cultures $\left(1.7 \times 10^{2} \mathrm{PFU} \cdot \mathrm{mL}^{-1}\right)$.

High-resolution confocal images of infected human basal epithelial cells showed that the viral antigen was displayed as clumps or as filaments (VFs) on the apical surface of infected basal cells $24-72 \mathrm{~h}$ post-infection (fig. 4c). The VFs closely resemble the structures seen by scanning electron microscopy and immunofluorescence on the surface of RSV-infected tissue culture cells [15].

Basal cell cultures infected with RSV increase secretion of inflammatory mediators associated with a Th2 response, together with monocyte chemoattractants

The spectrum of Th1- and Th2-associated cytokines produced by RSV infected cells is given in table 3 . Among the 10 measured, one Th1 cytokine (tumour necrosis factor (TNF)- $\alpha$ ) and four Th2 cytokines (interleukin (IL)-5, IL-6, IL-10 and IL-13) showed a significant $(\mathrm{p}<0.05)$ increase in levels produced by RSV infected human basal cell cultures compared with noninfected controls. TNF- $\alpha$ and IL- 6 showed the

\section{TABLE 2 Analysis of ciliated epithelial ultrastructure by transmission electron microscopy}

\section{Ultrastructure parameter}

Nonciliated cells

Control

68 (53.3-68.9)

$3.1(0.6-4.9)$

$38.1(27.9-42.4)$

$23.9(12-26.3)$

$18.5(17-36.6)$

Dead cells

Cells extruding from the surface

cytoplasmic blebbing

damage

arm defects

Loss of cilia
Ciliated cells

Control

RSV-infected

$38.7(35.6-44.1)$

$2.4(0-2.6)$

$35.1(25-39.6)$

$21.5(18.6-29.3)$

$30.6(20.7-44.7)^{*}$

$5.5(4.2-8)$

$5.7(3.3-7.5)$

$60.4(35.7-79) * *$

Data are presented as median (interquartile range) of all cells examined. RSV: respiratory syncytial virus. For three paired individuals, p-values were significantly different from the control. ${ }^{*}: p<0.05 ;{ }^{* *}: p<0.01$. 

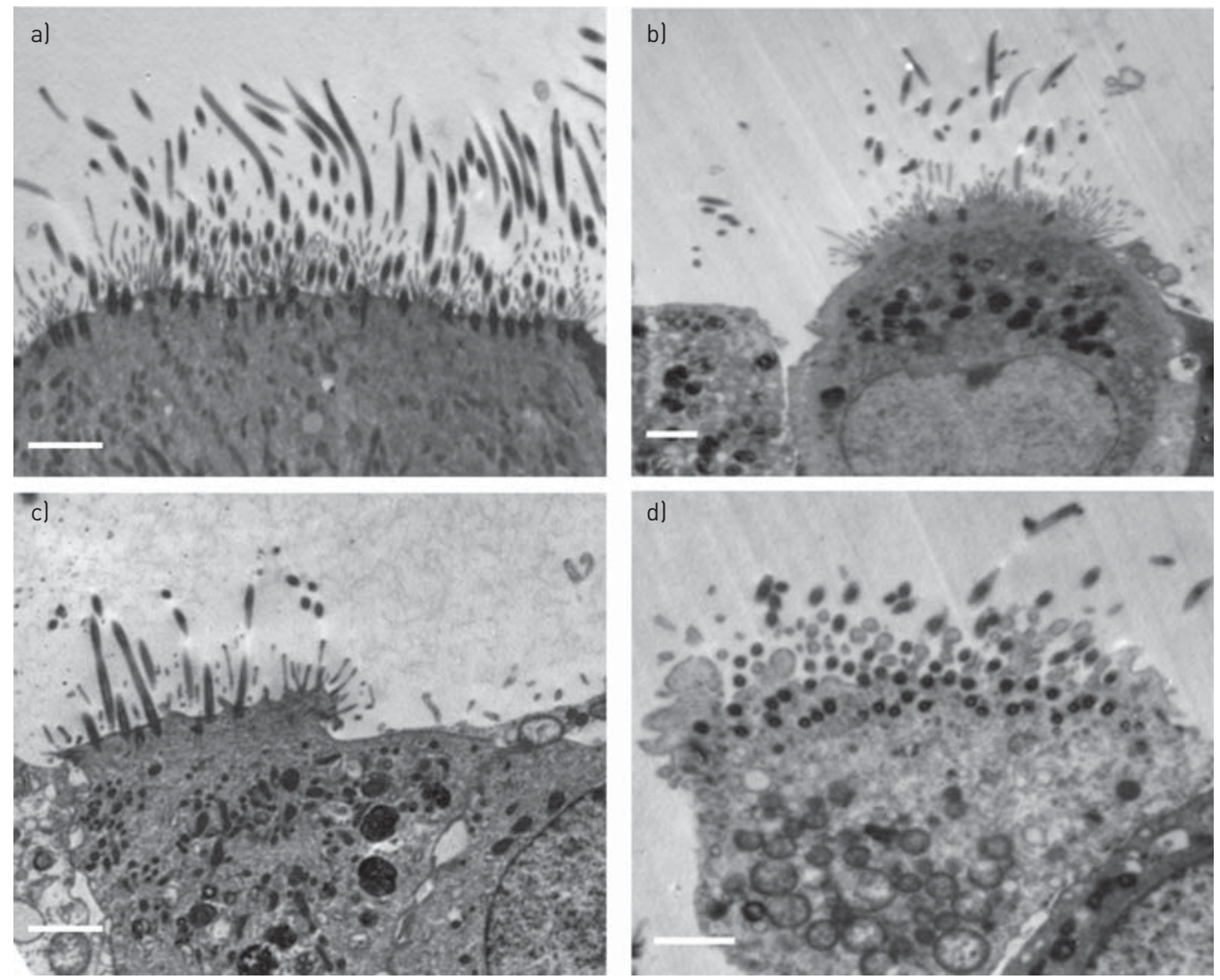

FIGURE 2 Transmission electron microscopy of ciliated respiratory epithelium grown at an air-liquid interface. a) A noninfected control showing normal mitochondria. b-d) Respiratory syncytial virus-infected epithelium showing b) a projecting cell with gaps developing between adjacent cells and abnormal swollen mitochondria, c) disruption of a tight junction with separation of cells and a reduction in numbers of cilia, and d) grossly abnormal cells with cytoplasmic blebbing, grossly swollen mitochondria and breakdown of cellular junctions. Scale bars $=2 \mu \mathrm{m}$.

highest increases following RSV infection, with a greater than three-fold change compared with the control. Levels of TNF- $\alpha$ increased from a median (interquartile range) concentration of $29(26-60) \mathrm{pg} \cdot \mathrm{mL}^{-1}$ to 178 (70-310) $\mathrm{pg} \cdot \mathrm{mL}^{-1}$ and IL-6 increased from $73(38-126) \mathrm{pg} \cdot \mathrm{mL}^{-1}$ to $226(141-712) \mathrm{pg} \cdot \mathrm{mL}^{-1}$. RSV-infected basal cells also produced significantly $(\mathrm{p}<0.05)$ higher levels of chemokines $(\mathrm{C}-\mathrm{C}$ motif) ligand $(\mathrm{CCL}) 26$, CCL2, CCL13 and C-X-C motif chemokine (CXCL) 8 compared with healthy controls (table 4). In particular, the concentration of monocyte chemoattractants CCL2 and CCL13 were high in basal cell cultures following RSV infection. Levels of CCL13 increased almost eight-fold, on average from a median (interquartile range) of $11(6-16) \mathrm{pg} \cdot \mathrm{mL}^{-1}$ to $111(28-163) \mathrm{pg} \cdot \mathrm{mL}^{-1}$.

Ciliated epithelial cells infected with RSV showed a significant increase in levels of one Th1 cytokine (IL$12^{\mathrm{p} 70}$ ) and two Th2 cytokines (IL-5 and IL-6) (table 3). IL-6 showed the greatest change with a more than two-fold increase from $424(294-536) \mathrm{pg} \cdot \mathrm{mL}^{-1}$ to $828(650-1341) \mathrm{pg} \cdot \mathrm{mL}^{-1}$, which was similar to RSV infected basal cell cultures. Unlike the RSV-infected basal cell cultures, only one monocyte chemoattractant protein (CCL13) was increased following RSV infection of ciliated cultures. There was a greater proportion of CXC chemokines (CXCL8 and CXCL10), which induce the migration of neutrophils from RSV-infected ciliated cultures. CXCL10 increased from a median (interquartile range) of 698 (433-974) $\mathrm{pg} \cdot \mathrm{mL}^{-1}$ to 4140 (823-19884) $\mathrm{pg} \cdot \mathrm{mL}^{-1}$ in this model. Interestingly, the concentration of both interferon (IFN) $\gamma$ and IL-4 produced by RSV-infected basal and ciliated cell cultures were highly positively correlated $\left(\mathrm{R}^{2}=0.993\right)$.

\section{Discussion}

For the first time, we have identified increased ciliary dyskinesia as early feature of RSV infection of human ciliated epithelial cells. Using high-speed videomicroscopy, we have shown that RSV infection increases the number of cilia with an abnormal beat pattern as early as $24 \mathrm{~h}$ post-infection. Electron micrographs of RSVinfected epithelium revealed increased cilia shedding from ciliated cells $72 \mathrm{~h}$ post-infection, which is consistent with our previous observations of airway epithelium obtained from paediatric infants with acute 

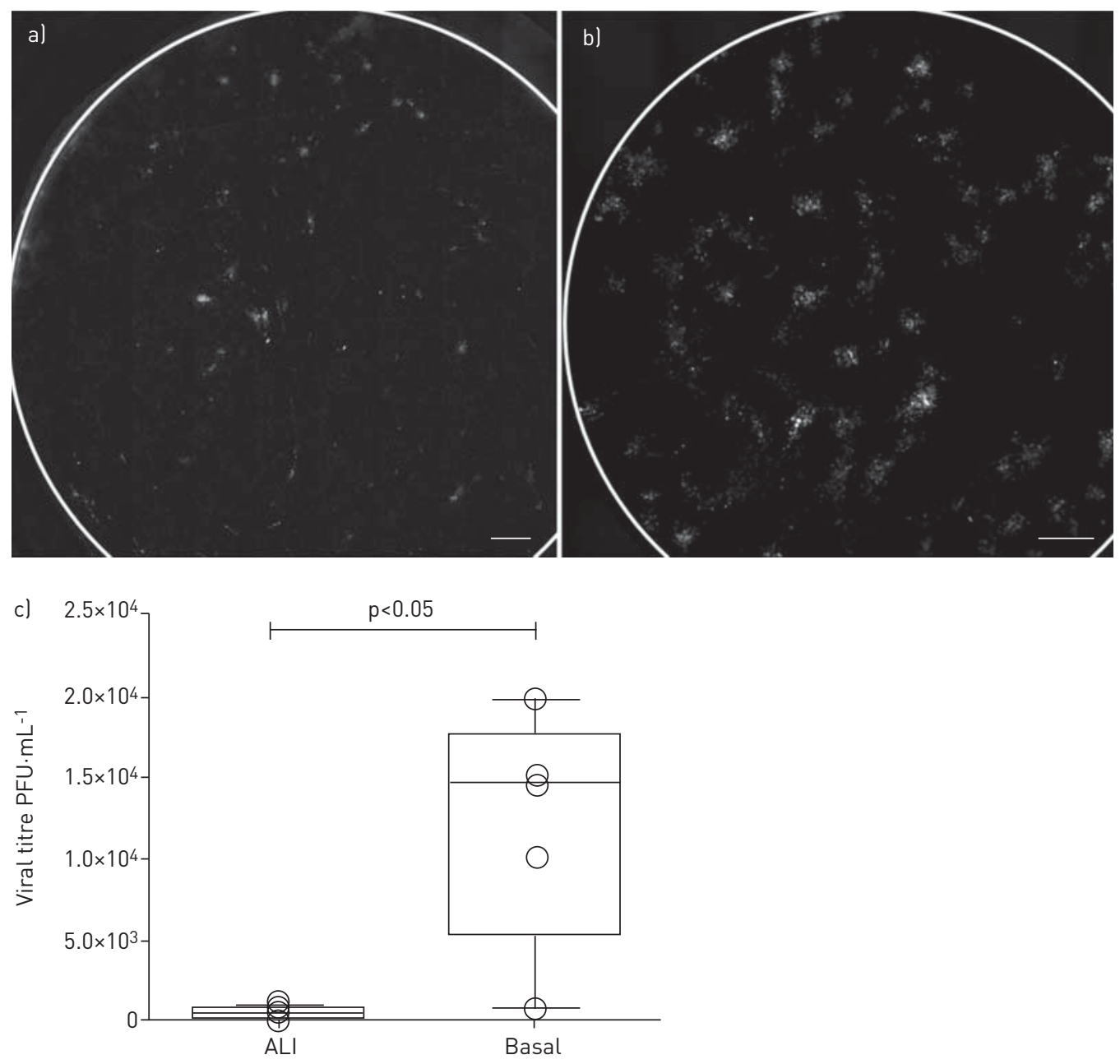

FIGURE 3 Low magnification $(10 \times)$ scans of a) a transwell insert containing human respiratory ciliated cells infected with respiratory syncytial virus (RSV) for $72 \mathrm{~h}$, and b) a well of a 24-well plate containing human respiratory basal cells infected with RSV for $72 \mathrm{~h}$. Images show that basal cell cultures supported more viral replication and displayed a greater proportion of RSV-infected cells after $72 \mathrm{~h}$ than ciliated cells. Cells were stained for RSV antigens and labelled with a secondary anti-goat antibody conjugated to fluorescein isothiocyanate. Images are representative of at least five biological repeats. Scale bars $=1 \mathrm{~mm}$. c) The viral titre (plaque-forming units $(\mathrm{PFU})$ per $\mathrm{mL}$ ) of supernatants collected from basal cell and air-liquid interface (ALI) cultures infected with RSV for $72 \mathrm{~h}$, showing significantly more viral progeny, were produced in infected basal cells compared with ciliated cell cultures $(n=5)$.

viral bronchiolitis [5]. The combination of increased ciliary dyskinesia and ciliary loss are likely to significantly reduce mucociliary clearance.

Our study also confirms the previous suggestion that ciliated cells are the target of RSV infection [2,3]. Our study collected evidence using electron and confocal microscopy from RSV-infected and uninfected ciliated epithelium. Electron micrographs of RSV-infected epithelium revealed mitochondrial damage that was specific to ciliated cells. Using immunofluorescence confocal microscopy, we observed the co-localisation of RSV and cilia antigens indicating a predilection of the virus to multiply in ciliated, as opposed to nonciliated, epithelial cells. We found during early infection, a high level of RSV antigen accumulated on the apical cell surface of the ciliated cell with initial sparing of the ciliary axoneme (fig. 1e-h). $24 \mathrm{~h}$ after infection, viral antigen was seen to be present at positions higher up the cilium shaft and closer to the ciliary tip (fig. 1i-1). This initial absence of RSV antigen from the distal regions of the cilia may be explained by the presence of a selective barrier at the base of the cilia, which has been shown to gate protein access to the axoneme during ciliogenesis [16]. Thus, viral antigen transport to the ciliary tip may be dependent on the disruption of this barrier.

Interestingly, we found RSV infection neither reduced CBF nor reduced the number of motile ciliated cells observed under light microscopy. These findings are consistent with other studies that used light microscopy as the principal method for detecting cytopathology $[2,3,8,17]$. To our knowledge, there has 

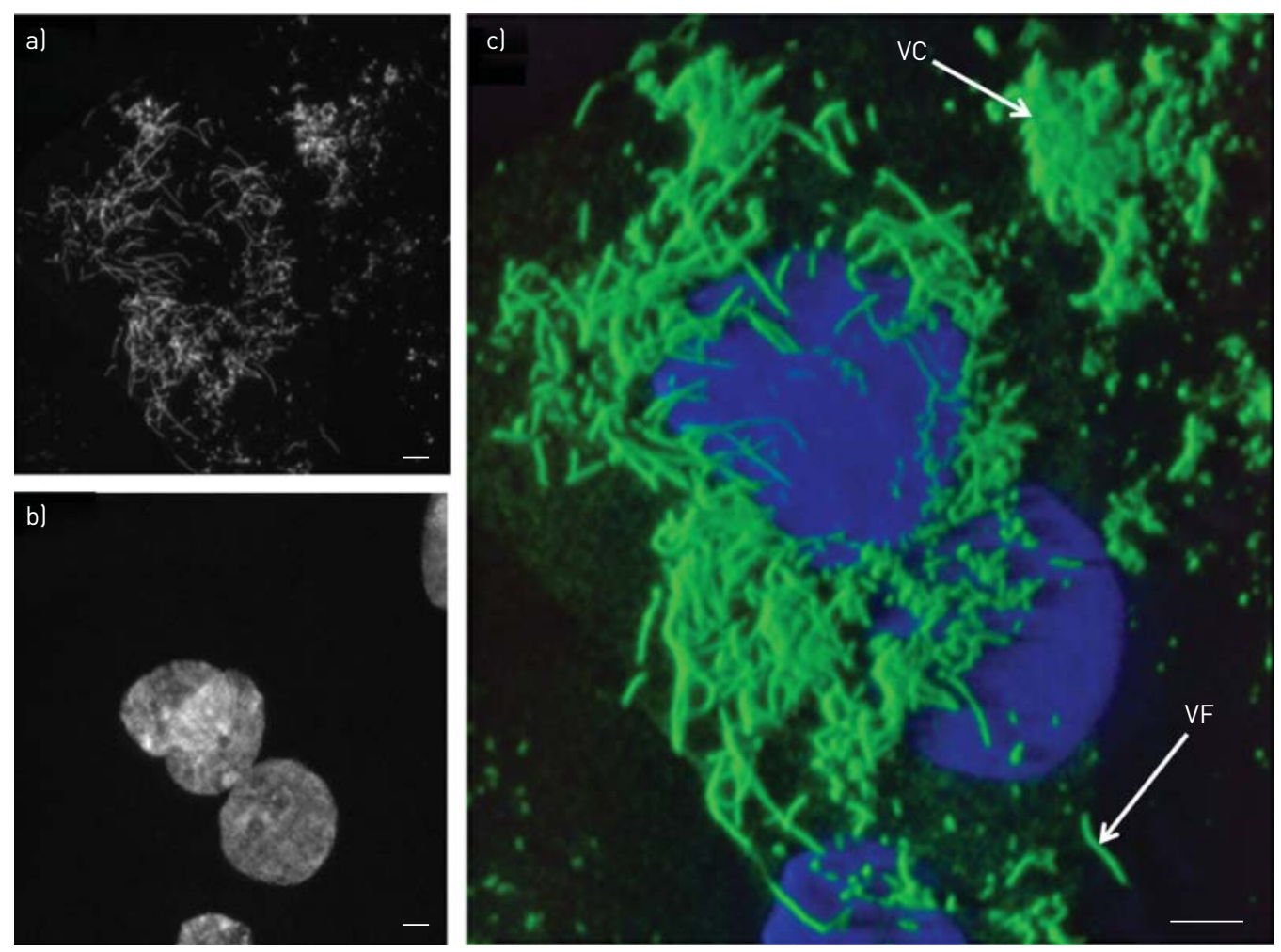

FIGURE 4 Confocal image of an respiratory syncytial virus (RSV)-infected human nasal epithelial basal cell. a) Cells were stained with an antibody specific for RSV antigens and labelled with a secondary anti-goat antibody conjugated to fluorescein isothiocyanate (green in merge c). b) Nuclei were stained using Hoescht (blue in merge). c) Cultures revealed syncytia formation after RSV infection, as observed by the proximity of the nuclei. VC: viral clumps; VF: viral filaments. Three-dimensional reconstruction of all channels was performed with Imaris blend filter (Bitplane AG, Zurich, Switzerland). Scale bar $=2 \mu \mathrm{m}$.

only been one study that has observed the gross cytopathic effects of RSV infection on human ciliated cell cultures [6]. That study reported a significant reduction in CBF almost immediately after exposure to RSV, with complete ciliostasis as early as $6 \mathrm{~h}$ post-infection [9]. In our experience the rapid onset of ciliostasis is frequently attributed to the presence of a toxin or to the nonphysiological nature of the carrier fluid; solutions with a low $\mathrm{pH}$ can cause rapid ciliostasis [18]. Another study reported that the addition of unwashed ultraviolet-irradiated RSV increased toxicity to HeLa cells, suggesting their viral preparation may have contained a toxic contaminant [13]. However, it is possible that the factors other than the presence of virus resulted in the rapid ciliostasis seen in the study by Tristram et al. [6].

Our infection model represents a differentiated and heterogeneous human airway epithelium that is independent of systemic signalling molecules and immune cells. Our data suggest that in the early stage of RSV infection, the inflammatory cells that are seen in the airways of patients with RSV infection are not responsible for virus-induced cytopathology.

The second aspect of our study was to investigate the effect of RSV infection of primary basal cells. We observed infected basal cell cultures using high-resolution confocal imaging and found that they displayed viral antigen as clumps or as filaments on the apical surface. Studies using light and electron microscopy have previously shown filamentous projections on the surface of RSV-infected cells [15], and these are thought to be largely responsible for the transmission of the virus to neighbouring cells [19]. We also observed that basal cell cultures produced a greater proportion of RSV-infected cells (fig. 3) after $72 \mathrm{~h}$ and we detected a higher viral titre in the apical supernatant compared with ciliated ALI cultures. Furthermore, the pattern of viral spread differed as RSV infection of ciliated cultures remained focal to ciliated areas, whereas almost all cells in the basal cell monolayer became infected. This was interesting, as previous reports suggest that basal cells are not the target of RSV [2, 4], which contradicts other reports that RSV replicates to high titres in epithelial cell lines (HEp-2) [8]. In our study, we infected both primary basal and ciliated cultures with RSV, in some cases using cells obtained from the same individual $(n=2)$. This novel approach allowed the ability of the virus to replicate in these two systems to be assessed more accurately than before. These data demonstrate that RSV can readily infect and replicate within basal cells and indicate that the 
TABLE 3 Apical levels of cytokines obtained from healthy human nasal epithelial cell cultures ${ }^{\#}$

\begin{tabular}{|c|c|c|c|c|c|c|}
\hline Cytokine & \multicolumn{3}{|c|}{ Basal cells } & \multicolumn{3}{|c|}{ Ciliated cells } \\
\hline INF- $\gamma \mathrm{pg} \cdot \mathrm{mL}^{-1}$ & $24(23-31)$ & $34(24-53)$ & $1.4(0.9-1.9)$ & 68 (57-105) & 95 (69-143) & $1.4(1.0-1.7)$ \\
\hline $\mathrm{IL}-1 \beta \mathrm{pg} \cdot \mathrm{mL}^{-1}$ & $9(6-10)$ & $11(9-37)$ & $1.8(0.8-3.3)$ & $35(32-45)$ & $40(28-69)$ & $1.0(0.8-1.6)$ \\
\hline $\mathrm{IL}-2 \mathrm{pg} \cdot \mathrm{mL}^{-1}$ & $5(5-7)$ & $9(5-18)$ & $1.5(1.2-2.9)$ & $26(17-28)$ & $22(20-27)$ & $1.1(0.9-2.0)$ \\
\hline \multicolumn{7}{|l|}{ Th2 } \\
\hline $\mathrm{IL}-4 \mathrm{pg} \cdot \mathrm{mL}^{-1}$ & $2(2-3)$ & $3(3-6)$ & $1.2(1.0-1.9)$ & $8(6-11)$ & $9(6-14)$ & $1.2(0.9-1.4)$ \\
\hline $\mathrm{IL}-5 \mathrm{pg} \cdot \mathrm{mL}^{-1}$ & $5(5-9)$ & $9(7-19) *$ & $2.0(1.0-2.7)$ & $23(21-29)$ & $37(33-42) *$ & $1.4(1.3-1.7)$ \\
\hline $\mathrm{IL}-10 \mathrm{pg} \cdot \mathrm{mL}^{-1}$ & $8(6-10)$ & $16(13-30)^{*}$ & $2.2(1.4-3.5)$ & $62(41-85)$ & $75(60-104)$ & $1.1(0.9-1.2)$ \\
\hline $\mathrm{IL}-13 \mathrm{pg} \cdot \mathrm{mL}^{-1}$ & $10(8-21)$ & $27(15-39)^{*}$ & $1.9(1.5-2.0)$ & $67(53-75)$ & 69 (52-99) & $1.0(0.9-1.5)$ \\
\hline $\mathrm{IL}-6 \mathrm{pg} \cdot \mathrm{mL}^{-1}$ & $73(38-126)$ & $226(141-712)^{*}$ & $3.1(1.7-5.8)$ & $424(294-536)$ & $828(650-1341) *$ & $2.3(1.4-2.8)$ \\
\hline
\end{tabular}

Data are presented as median (interquartile range). RSV: respiratory syncytial virus; Th: T-helper cell; IFN: interferon; IL: interleukin; TNF: tumour necrosis factor. " : $n=8 ;$ ": fold change from uninfected control at same time point. *: $p<0.05$ (Wilcoxon signed rank test).

basal cells present in a pseudo-stratified culture maybe less permissive to RSV infection than those in a monolayer culture. Reasons for this may be due to the location of the receptor in polarised cell cultures, which may restrict viral entry to the apical surface as has been previously suggested [20]. Alternatively, there may be a difference in the growth phase exhibited by basal cells in a monolayer compared with those that have reached terminal differentiation. ZHANG et al. [2] showed that as cells differentiate into a ciliated phenotype they became more susceptible to RSV infection and had a higher proportion of viral infected cells. However, in the study by ZHANG et al. [2], 15 days after ALI culture, this increase reached a plateau, with no further increase in viral replication reported [2]. This may be due to the cells entering a different growth phase. WU et al. [21] recently reported that primary basal epithelial cells increase RSV production if arrested in the first gap phase (G1) of the cell cycle, when protein translation is maximal in the cell. To our knowledge, there are no studies reporting the growth phase of basal cells in terminally differentiated cell cultures, and our data suggest that this is worthy of investigation.

Another explanation for the difference in viral titre produced by infected basal and ciliated cell cultures is the presence of secreted factors that may protect the ciliated epithelium from RSV. It is known that the ciliated epithelium secretes a number of anti-viral and anti-microbial agents, including defensins and antimicrobial peptides. In our study, the level of the anti-viral cytokine interferon- $\gamma$ was three-fold higher in the

TABLE 4 Apical chemokine response from human nasal epithelial cell cultures infected with respiratory syncytial virus (RSV) for $72 h^{\#}$

\begin{tabular}{|c|c|c|c|c|c|c|}
\hline Chemokine & \multicolumn{3}{|c|}{ Basal cells } & \multicolumn{3}{|c|}{ Ciliated cells } \\
\hline MIP-1 $\beta$ CCL4 $\mathrm{pg} \cdot \mathrm{mL}^{-1}$ & $3(1-7)$ & $13(4-41)$ & $3.9(1.2-5.5)$ & $33(17-54)$ & $37(33-52)$ & $1.3(1.0-1.8)$ \\
\hline Eotaxin-3 CCL26 pg $\cdot \mathrm{mL}^{-1}$ & $233(190-398)$ & $1146(192-7398) *$ & $2.1(1.2-17.7)$ & 6593 (3932-11580) & 5516 (4564-8620) & $0.8(0.7-1.1)$ \\
\hline TARC CCL17 $\mathrm{pg} \cdot \mathrm{mL}^{-1}$ & $54(46-83)$ & 100 (69-189) & $1.2(1.1-2.5)$ & $295(227-415)$ & 339 (302-368) & $1.1(1.0-1.3)$ \\
\hline MCP-4 CCL13 pg $\cdot \mathrm{mL}^{-1}$ & $11(6-16)$ & $111(28-163)^{*}$ & $7.5(6.0-15.4)$ & $94(42-134)$ & $274(95-337)^{*}$ & $2.5(2.1-3.0)$ \\
\hline IL-8 $\mathrm{CXCL} 8 \mathrm{pg} \cdot \mathrm{mL}^{-1}$ & $95(79-143)$ & $208(77-554)^{*}$ & $1.7(1.1-3.4)$ & $594(506-989)$ & $887(692-1190) *$ & $1.5(1.2-1.6)$ \\
\hline $\mathrm{IP}-10 \mathrm{CXCL} 10 \mathrm{pg} \cdot \mathrm{mL}^{-1}$ & $95(87-115)$ & $239(103-560)$ & $1.8(1.1-5.9)$ & $698(433-974)$ & 4140 (823-19884)* & $3.5(1.8-20.2)$ \\
\hline
\end{tabular}

Data are presented as median (interquartile range). CCL: (C-C motif) ligand; MIP: macrophage inflammatory protein; TARC: thymus and activation regulated chemokine; MCP: monocyte chemotactic protein; MDC: macrophage-derived chemokine; IL: interleukin; CXCL: C-X-C motif chemokine; IP: interferon- $\gamma$-induced protein. ${ }^{\#}: \mathrm{n}=8 ;{ }^{\circ}$ : fold change from uninfected control at same time-point. ${ }^{*}: \mathrm{p}<0.05$ (Wilcoxon signed rank test). 
ciliated cell system compared with the basal cell system, and this may reduce viral yield through the activation of host transcription factors [22]. However, there are limitations in directly comparing these two culture systems. For example, the number of cells per well is lower in a basal cell monolayer compared with a pseudo-stratified ciliated culture, ALI medium contains growth factors required for ciliogenesis that are absent in basal cell medium, and basal cell cultures are submerged, so secreted factors are directly diluted in the growth media. To minimise these limitations, we looked at the pattern of inflammatory mediators produced by each model, rather than directly comparing the concentrations of each mediator. We found that basal cell cultures infected with RSV produced significantly higher levels of anti-inflammatory cytokines associated with a Th2 response (IL-10 and IL-13) and IL-6 compared with the uninfected control cells. Increased levels of eotaxin-3, which is an eosinophil chemoattractant and Th2 cell chemoattractant also fits with the Th2 cell selective bias of the basal cell response and IL-5, which was significantly increased following RSV infection, may support lymphocyte and eosinophil proliferation. Interestingly, monocyte chemoattractant protein (MCP) 1 and MCP4 were also increased with RSV. In contrast, the response of ciliated cell cultures to RSV was not markedly biased towards either a Th1- or Th2-associated response, but instead produced a strong signal for the recruitment of neutrophils (reflected in high levels of CXCL8). This is consistent with the observation that neutrophils are the dominant cell type recovered from bronchoalveolar lavage in infants with RSV bronchiolitis [23]. Furthermore, neutrophils are thought to augment RSV-induced epithelial damage [24, 25], and the absence of these cells in our system may explain the lack of observed cytopathology. Ciliated cell cultures also show an elevated production of the IFN- $\gamma$ induced protein CXCL10 following RSV infection, which is consistent with previous studies [26]. Interestingly, we did not find a significant increase in the level of IFN- $\gamma$ following RSV infection. This is consistent with a recent study suggesting that type III IFN is the predominant IFN produced in RSVinfected nasal epithelial cells [27].

A limitation to our study was that we only assessed the apical secretion of cytokines from ALI cultures. Studies suggest that the secretion of cytokines following RSV infection is predominantly in the basolateral direction, and significant increases in basolateral levels of IL-6 [3, 7, 28], CXCL8 [3, 7, 28], CXCL10 [3] and RANTES (regulated on activation, normal T-cell expressed and secreted) [7] have been reported. There are also reports of increased apical secretion of IL-1 $\alpha$ [26], CXCL8 [6, 26], CXCL10 [26], CCL2 [26] and RANTES $[6,26]$ following RSV infection of differentiated primary human respiratory epithelial cells cultured at ALI. These studies measured cytokine production at different time-points, ranging from $24 \mathrm{~h}$ to $72 \mathrm{~h}$ post-RSV infection. Our results cover a broader spectrum of cytokines and chemokines and, therefore, give a more detailed view of the environment of the airway at $72 \mathrm{~h}$ post-RSV infection than previously reported. Additional inflammatory mediators have been shown to have an important role in the pathogenesis of RSV bronchiolotis [29] and this model will allow for further investigation.

In summary, this study has revealed epithelial damage to ciliated cell cultures infected with RSV was minor and restricted primarily to ciliated cells. We have shown that these cells produce a strong signal for the recruitment of neutrophils, which is consistent with clinical picture seen in children with RSV bronchiolitis. We confirm the predilection of RSV to infect ciliated epithelial cells with visible viral antigen on the surface of the ciliary axoneme. We have also shown that RSV infection of ciliated respiratory epithelial cells leads to ciliary dyskinesia that occurs before other obvious cytopathology is present, while cilia still maintain a normal ciliary beat frequency. Increased ciliary dyskinesia combined with ciliary loss and epithelial damage is likely to result in reduced mucociliary clearance early in the infective process. These findings highlight the role of ciliated cells in the establishment of RSV infection and important differences that may be seen, depending on the model of infection.

\section{References}

1 Reed G, Jewett PH, Thompson J, et al. Epidemiology and clinical impact of parainfluenza virus infections in otherwise healthy infants and young children $<5$ years old. J Infect Dis 1997; 175: 807-813.

2 Zhang L, Peeples ME, Boucher RC, et al. Respiratory syncytial virus infection of human airway epithelial cells is polarized, specific to ciliated cells, and without obvious cytopathology. J Virol 2002; 76: 5654-5666.

3 Villenave R, Thavagnanam S, Sarlang S, et al. In vitro modeling of respiratory syncytial virus infection of pediatric bronchial epithelium, the primary target of infection in vivo. Proc Natl Acad Sci USA 2012; 109: 5040-5045.

4 Mellow TE, Murphy PC, Carson JL, et al. The effect of respiratory synctial virus on chemokine release by differentiated airway epithelium. Exp Lung Res 2004; 30: 43-57.

5 Wong JY, Rutman A, O'Callaghan C. Recovery of the ciliated epithelium following acute bronchiolitis in infancy. Thorax 2005; 60: 582-587.

6 Tristram DA, Hicks W Jr, Hard R. Respiratory syncytial virus and human bronchial epithelium. Arch Otolaryngol Head Neck Surg 1998; 124: 777-783.

7 Das S, Palmer OP, Leight WD, et al. Cytokine amplification by respiratory syncytial virus infection in human nasal epithelial cells. Laryngoscope 2005; 115: 764-768.

8 Wright PF, Ikizler MR, Gonzales RA, et al. Growth of respiratory syncytial virus in primary epithelial cells from the human respiratory tract. J Virol 2005; 79: 8651-8654. 
Chilvers MA, O'Callaghan C. Analysis of ciliary beat pattern and beat frequency using digital high speed imaging: comparison with the photomultiplier and photodiode methods. Thorax 2000; 55: 314-317.

10 Stannard WA, Chilvers MA, Rutman AR, et al. Diagnostic testing of patients suspected of primary ciliary dyskinesia. Am J Respir Crit Care Med 2010; 181: 307-314.

11 Chilvers MA, McKean M, Rutman A, et al. The effects of coronavirus on human nasal ciliated respiratory epithelium. Eur Respir J 2001; 18: 965-970.

12 Hirst RA, Rutman A, Williams G, et al. Ciliated air-liquid cultures as an aid to diagnostic testing of primary ciliary dyskinesia. Chest 2010; 138: 1441-1447.

13 Bataki EL, Evans GS, Everard ML. Respiratory syncytial virus and neutrophil activation. Clin Exp Immunol 2005; 140: 470-477.

14 Thomas B, Rutman A, Hirst RA, et al. Ciliary dysfunction and ultrastructural abnormalities are features of severe asthma. J Allergy Clin Immunol 2010; 126: 722-729.

15 Parry JE, Shirodaria PV, Pringle CR. Pneumoviruses: the cell surface of lytically and persistently infected cells. J Gen Virol 1979; 44: 479-491.

16 Craige B, Tsao CC, Diener DR, et al. CEP290 tethers flagellar transition zone microtubules to the membrane and regulates flagellar protein content. J Cell Biol 2010; 190: 927-940.

17 Saito T, Deskin RW, Casola A, et al. Respiratory syncytial virus induces selective production of the chemokine RANTES by upper airway epithelial cells. J Infect Dis 1997; 175: 497-504.

18 Hirst RA, Rutman A, Sikand K, et al. Effect of pneumolysin on rat brain ciliary function: comparison of brain slices with cultured ependymal cells. Pediatr Res 2000; 47: 381-384.

19 Jeffree CE, Brown G, Aitken J, et al. Ultrastructural analysis of the interaction between F-actin and respiratory syncytial virus during virus assembly. Virology 2007; 369: 309-323.

20 Roberts SR, Compans RW, Wertz GW. Respiratory syncytial virus matures at the apical surfaces of polarized epithelial cells. J Virol 1995; 69: 2667-2673.

21 Wu W, Munday DC, Howell G, et al. Characterization of the interaction between human respiratory syncytial virus and the cell cycle in continuous cell culture and primary human airway epithelial cells. J Virol 2011; 85: 10300-10309.

22 Zdrenghea MT, Telcian AG, Laza-Stanca V, et al. RSV infection modulates IL-15 production and MICA levels in respiratory epithelial cells. Eur Respir J 2012; 39: 712-720.

23 McNamara PS, Ritson P, Selby A, et al. Bronchoalveolar lavage cellularity in infants with severe respiratory syncytial virus bronchiolitis. Arch Dis Child 2003; 88: 922-926.

24 Jones A, Qui JM, Bataki E, et al. Neutrophil survival is prolonged in the airways of healthy infants and infants with RSV bronchiolitis. Eur Respir J 2002; 20: 651-657.

25 Wang SZ, Xu H, Wraith A, et al. Neutrophils induce damage to respiratory epithelial cells infected with respiratory syncytial virus. Eur Respir J 1998; 12: 612-618.

26 Oshansky CM, Barber JP, Crabtree J, et al. Respiratory syncytial virus F and G proteins induce interleukin $1 \alpha$, CC, and CXC chemokine responses by normal human bronchoepithelial cells. J Infect Dis 2010; 201: 1201-1207.

27 Okabayashi T, Kojima T, Masaki T, et al. Type-III interferon, not type-I, is the predominant interferon induced by respiratory viruses in nasal epithelial cells. Virus Res 2011; 160: 360-366.

28 Hackett TL, Singhera GK, Shaheen F, et al. Intrinsic phenotypic differences of asthmatic epithelium and its inflammatory responses to respiratory syncytial virus and air pollution. Am J Respir Cell Mol Biol 2011; 45: 1090-1100.

29 Schuurhof A, Bont L, Hodemaekers HM, et al. Proteins involved in extracellular matrix dynamics are associated with respiratory syncytial virus disease severity. Eur Respir J 2012; 39: 1475-1481. 